\title{
Effect of silica fume content on microstructure development and bond to steel fiber in ultra-high strength cement-based materials (UHSC)
}

\author{
Zemei Wu ${ }^{\text {a,b }}$, Caijun Shi ${ }^{a^{*}}$, K.H. Khayat ${ }^{b}$ \\ ${ }^{a}$ College of Civil Engineering, Hunan University, Changsha 410082, PR China \\ ${ }^{b}$ Department of Civil, Architectural and Environmental Engineering, Missouri University of Science and \\ Technology, Rolla, MO, 65401, USA
}

\begin{abstract}
The use of silica fume can significantly enhance mechanical properties of concrete given its beneficial filling and pozzolanic effects. In this study, a simple and effective double-side pullout testing method was adopted to characterize the interfacial bond properties, which include pullout load-slip relationship, bond strength, and pullout energy, of steel fiber-matrix in ultra-high strength cement-based material (UHSC) with 0-25\% silica fume by the mass of binder. The effects of silica fume content on flowability, heat of hydration, compressive and flexural strengths, hydration products, and pore structure of matrix at different curing time were evaluated as well. Backscatter scanning electron microscopy (BSEM) and micro-hardness measurement were used to examine the quality of interfacial transition zone (ITZ) around the fiber. In terms of the results, the optimal silica fume content could be in the range of $15 \%-25 \%$. UHSC mixtures with these dosages of silica fume showed significant improvement in pullout behavior. Its bond strength and pullout energy at $28 \mathrm{~d}$ could increase by $170 \%$ and $250 \%$ compared to the reference samples without any silica fume. The microstructural observation verified the findings on the macro-properties development. Formation of more and higher strength of hydration products and refinement of ITZ around the fiber ensured higher micro-hardness, and thus increased the bond to fiber.
\end{abstract}

Keywords: UHSC; Silica fume; Steel fiber; Compressive and flexural strengths; Microstructure; Fiber pullout behavior

*Corresponding author. Tel./fax: +86 73188823937.

E-mail address: cshi@hnu.edu.cn (C. Shi) 


\section{Introduction}

Ultra-high strength cement-based material (UHSC) is an advanced material characterized by use of high content of cementitious materials, sand, superplasticizer and/or fibers, and absence of coarse aggregate [1]. The very low water-to-binder ratio (w/b) and dense microstructure allow its high strength generally over $120 \mathrm{MPa}$ and superior durability. However, the higher the compressive strength is, the more brittle the matrix becomes. Fiber has been proven as an essential part for UHSC $[2,3]$. With the incorporation of proper fibers, the initiation, propagation or coalescence of cracks can be efficiently controlled. Many types of fiber, such as carbon, steel, and polypropylene fibers have been used in UHSC. Steel fiber is the most commonly used one because of its superior tensile strength over $2000 \mathrm{MPa}$. The incorporation of such steel fiber ensures satisfactory mechanical properties, such as tensile, bending, and shear strengths of UHSC [4,5]. However, bond failure associated with fiber-matrix interface is the primary reason leading to the failure of the whole structure [6]. It was reported that there exists two different interfacial failure modes when steel fibers are pulled out from matrix [7]. One is adhesive failure often occurring at actual fiber-matrix interface, while the other one is adherent failure taking place in matrix. Both failure modes would directly lead to underutilization of fiber or matrix without fully exerting their own mechanical capacity, and eventually result in cracking of composites. Therefore, improvement in the bond properties between fiber and matrix is of great significance.

The performance of fiber reinforced composites is governed by the quality of matrix, geometry and type of fiber, and quality of interfacial transition zone (ITZ) between the fiber or aggregate and matrix [7-9]. Several strategies can be used to improve the bond properties at fiber-matrix interface, including: (1) densification of the cementitious matrix and ITZ [8,9]; (2) use of deformed fibers 
[4,10]; (3) surface treatment of fibers, such as plasma treatment for polyethylene fibers [7]. Because ITZ has a thickness varying between 10 and $100 \mu \mathrm{m}$, and contains large preferentially calcium hydroxide $(\mathrm{CH})$ crystals and high porosity [11,12], it is usually recognized as the weakest zone in concrete [13]. The basic strategy to improve the bond properties is densification of UHSC mixture and the ITZ as well. Many densification methods have been proposed, which include reduction in water-to-binder ratio, prolongation of moist curing, heat curing, and incorporation of mineral admixtures $[11,14]$. Incorporation of silica fume is one of the most effective and economic methods because of its fine particle size and high pozzolanic activity [15]. These two characteristics of silica fume can lead to remarkable reduction in porosity and permeability, as well as enhancement in strength and durability [15].

The interfacial bond properties of fiber-matrix interface in UHSC have been extensively investigated using pullout testing [16-18]. The studied factors include matrix composition, fiber shape, fiber inclination angle, fiber embedment length, curing condition, and use of micro fibers $[4,5,19]$. Generally, the pullout testing can be classified into single-sided and double-sided testing in terms of the methods of applying tensile force and/or fiber embedment [20]. The single-sided testing is relatively simple to be carried out. However, difficulty in gripping the free end of the fiber is inevitably encountered due to its very fine diameter [21]. To secure the reliability of the results, a large number of samples are required. Furthermore, the whole fiber is fully embedded in real composites, which is significantly different from that in the ideal test. The double-sided pullout testing was described by Chan et al [22]. Dog-bone samples with two separated halves from the sample center perpendicular to loading direction were used. In order to completely eliminate the adhesion of the two halves, one half sample was cast first, then the other half $24 \mathrm{~h}$ later. However, 
this makes the casting process complicated and time consuming. Therefore, to ensure proper interfacial stress transfer from fiber to matrix, so as to better evaluate the interfacial properties of fiber-matrix in UHSC, a simple and suitable method is needed.

Extensive researches have been conducted on UHSC, but few of them are related to the microstructure development, the bond of fiber-matrix interface, and the relationship between them. In this paper, the effect of silica fume content on flowability, heat of hydration, compressive and flexural strengths, and bond to steel fiber in UHSC were investigated. A simple and effective double-side pullout testing was used to evaluate the interfacial bond properties of steel fiber-matrix. Thermo-gravimetry (TG) analysis and mercury intrusion porosimetry (MIP) were used to characterize hydration products and pore structure of the matrix. Backscatter scanning electron microscopy (BSEM) and micro-hardness measurement were used to examine the quality of ITZ around the fiber, respectively. It should provide important implications to improve the tensile and toughness properties of UHSC.

\section{Experimental program}

\subsection{Materials}

Portland cement (P.I 42.5) complying with the Chinese Standards GB175-2007 was used [23]. Table 1 summarizes its main chemical composition and physical properties. Silica fume with a particle size in the range of $0.02-0.28 \mu \mathrm{m}$ was used. Its BET specific surface area was $18500 \mathrm{~m}^{2} / \mathrm{kg}$. The properties of the silica fume are also summarized in Table 1. 
Table 1 Chemical composition and physical properties of binder

\begin{tabular}{|c|c|c|c|}
\hline Materials & & Cement & Silica fume \\
\hline $\mathrm{SiO}_{2}(\%)$ & & 21.18 & 93.9 \\
\hline $\mathrm{Al}_{2} \mathrm{O}_{3}(\%)$ & & 4.73 & 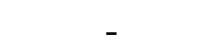 \\
\hline $\mathrm{Fe}_{2} \mathrm{O}_{3}(\%)$ & & 3.41 & 0.59 \\
\hline $\mathrm{SO}_{3}(\%)$ & & 2.83 & - \\
\hline $\mathrm{CaO}(\%)$ & & 62.49 & 1.85 \\
\hline $\mathrm{MgO}(\%)$ & & 2.53 & 0.27 \\
\hline $\mathrm{Na}_{2} \mathrm{O}(\%)$ & & - & 0.17 \\
\hline $\mathrm{K}_{2} \mathrm{O}(\%)$ & & - & 0.86 \\
\hline Loss on ignition (\%) & & 1.20 & 0.30 \\
\hline Blain surface area $\left(\mathrm{m}^{2} / \mathrm{kg}\right)$ & & 350 & - \\
\hline BET surface area $\left(\mathrm{m}^{2} / \mathrm{kg}\right)$ & & - & 18500 \\
\hline Specific gravity $\left(\mathrm{kg} / \mathrm{m}^{3}\right)$ & & 3140 & 2200 \\
\hline \multirow{2}{*}{ Setting time $(\mathrm{min})$} & Initial & 172 & - \\
\hline & Final & 222 & - \\
\hline Compressive strength (MPa) & $3 \mathrm{~d}$ & 28.30 & - \\
\hline Flexural strength (MPa) & $3 \mathrm{~d}$ & 5.60 & - \\
\hline
\end{tabular}

Natural river sand with a fineness modulus of 3.0 was used. Particles with size greater than 2.36 $\mathrm{mm}$ were removed by sieving.

A smooth straight brass-coated steel fiber with a diameter of $0.2 \mathrm{~mm}$ and length of $13 \mathrm{~mm}$ was used. Its tensile strength was approximately $2800 \mathrm{MPa}$.

A polycarboxylate-based superplasticizer (SP) with solid content of $20 \%$ and water-reducing efficiency greater than $30 \%$ was used.

2.2. Mixture proportions and sample preparation

UHSC specimens with five silica fume contents of $0,10 \%, 15 \%, 20 \%$, and $25 \%$ by the total mass of binder were prepared. The mixture proportions are reported in Table 2. The mixtures were designated as U0, U10, U15, U20, and U25, respectively. Based on the previous study [24], w/b of 0.18 was used and the dosage of SP was fixed at $2 \%$ by the total mass of binder.

For preparation of mixtures, the powder ingredients were dry-mixed at a low speed for $3 \mathrm{~min}$, 
then water and SP were slowly added. The material was then mixed for $6 \mathrm{~min}$ at low speed and $1 \mathrm{~min}$ at high speed.

Table 2 Mixture proportion of UHSC

\begin{tabular}{ccccccc}
\hline \multirow{2}{*}{ No. } & \multirow{2}{*}{ w/b } & \multicolumn{5}{c}{ Mass of Ingredient $\left(\mathrm{kg} / \mathrm{m}^{3}\right)$} \\
\cline { 3 - 7 } & & $\mathrm{W}$ & Sand & $\mathrm{C}$ & $\mathrm{SF}$ & $\mathrm{SP}^{*}$ \\
\hline U0 & 0.18 & 177 & 1079 & 1079 & 0 & 21.6 \\
U10 & 0.18 & 177 & 1079 & 971 & 108 & 21.6 \\
U15 & 0.18 & 177 & 1079 & 917 & 162 & 21.6 \\
U20 & 0.18 & 177 & 1079 & 863 & 216 & 21.6 \\
U25 & 0.18 & 177 & 1079 & 809 & 270 & 21.6 \\
\hline
\end{tabular}

$\mathrm{SP}^{*}$ : total mass of liquid-based SP

2.3. Experimental methods

\subsubsection{Flowability}

The fresh mortar was filled into a mini cone placed on an automatic jump table as described in Chinese standard of GB2419-2005 [25]. The mini cone has an upper diameter of $70 \mathrm{~mm}$, a lower diameter of $100 \mathrm{~mm}$, and a height of $60 \mathrm{~mm}$. After mini cone was vertically lifted, the mortar was vibrated automatically for 25 times. Two diameters perpendicular to each other were then determined and mean value was reported.

\subsubsection{Heat of hydration}

A TAM air isothermal calorimeter was used to measure the heat of hydration of the binder mixtures at a constant temperature of $20^{\circ} \mathrm{C}$. This instrument has eight sample chambers fitted inside one thermostat to make eight measurements simultaneously.

Based on the mixture proportion and sample preparation procedure as described above, five cement pastes were prepared. Approximately $4 \mathrm{~g}$ paste of each mixture was weighed and placed into a sealed glass ampoule. Then they were placed into the isothermal calorimeter for measuring heat of 
hydration for $60 \mathrm{~h}$.

\subsubsection{Testing of flexural and compressive strengths}

Specimens of $40 \times 40 \times 160 \mathrm{~mm}$ were cast for determination of compressive and flexural strengths. Three samples of each batch were tested. They were demolded $24 \mathrm{~h}$ after casting then cured in lime-saturated water until the age of $1,3,7,28$, and $91 \mathrm{~d}$. The bending and compressive strength tests of cement mortar were conducted according to GB/T 17671-1999 (similar to ISO 697:1989) [26]. Three-point bending testing was first performed to obtain flexural strength. Then the six broken specimens were used to test compressive strength. The mean values of three flexural strengths and six compressive strengths were reported.

\subsubsection{Fiber pullout testing}

Dog-bone shape specimens were used to measure the pullout behavior of four embedded steel fibers within mortars, as shown in Fig. 1. The specimen was divided into two halves, namely a pullout half and a fixed half using a plastic clip at the center with four fibers perpendicularly installed to it. For the fiber holding and casting process, plastic clips with specified dimensions corresponding to the molds were manually cut first. The plastic clips were punched to get four holes with an evenly distributed space of $15 \mathrm{~mm}$, as shown in Fig. 1. Four fibers were come through the four holes, respectively. By using a self-made bamboo substrate with designed four vertical holes with depth of $5 \mathrm{~mm}$, the fibers length ( $5 \mathrm{~mm}$ in the pullout half) and orientation were ensured. After that, the fibers were fixed in the plastic clips by using super glue. Then the plastic clips were first put into two parallel slots located at the center of steel mold. In order to completely prevent adhesion of 
the two halves of the matrix, a plastic film was used to cover the whole casting zone in the mold through crossing the plastic clip. The matrix was then cast into the mold. The specimens were demolded $24 \mathrm{~h}$ after casting and cured in lime-saturated water for 1, 3, 7, 28, and $91 \mathrm{~d}$.

An MTS testing machine with $20 \mathrm{KN}$ load cell was used to carry out the pullout testing following CECS13-2009 [27], as shown in Fig. 2. The loading rate was $1 \mathrm{~mm} / \mathrm{min}$. Only the pullout strength and pullout energy of those samples with all four fibers pulled out from the short embedment length section were used. For each matrix, five specimens were tested. The bond strength was calculated as follows:

$$
\tau_{\max }=\frac{P_{\max }}{n \pi d l}
$$

where $\tau_{\max }(\mathrm{MPa})$ is the bond strength of embedded fiber based on the maximum pullout load; $P_{\max }$ $(\mathrm{N})$ is the maximum pullout load; $d(\mathrm{~mm})$ is the diameter of a single fiber; $l(\mathrm{~mm})$ is the embedment length of the fiber in pullout half $(5 \mathrm{~mm}) ; n$ is the number of fibers embedded in a dog-bone specimen (4).

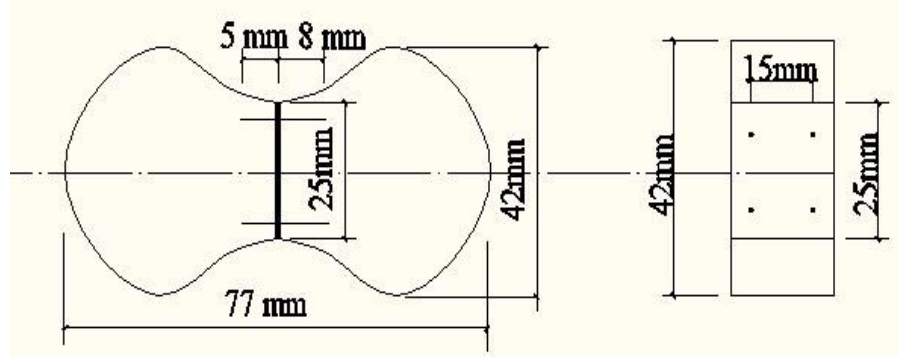

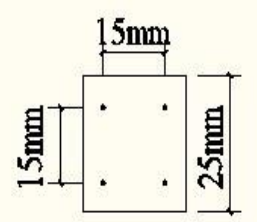

Fig. 1 Illustration of dog-bone shape specimen

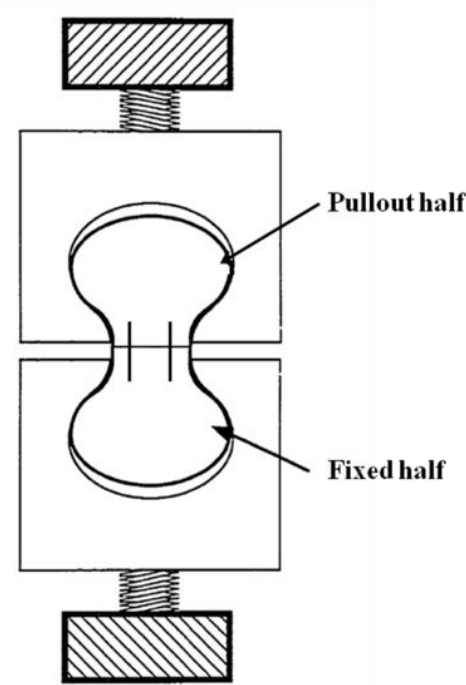

Fig. 2 Illustration of pullout test apparatus 


\subsubsection{Thermal-gravimetric analysis}

Thermo-gravimetry (TG) and derivative thermo-gravimetry (DTG) analyses were used to quantitatively estimate the amount of hydration products in the UHSCs. Samples taken from UHSC matrix were put into a vacuum drying chamber to reach constant mass. After that, these dried samples were ground to powder and sieved on a $45 \mu \mathrm{m}$ sieve. A sample of 10-15 mg was heated from 20 to $1000^{\circ} \mathrm{C}$ in a nitrogen gas flow at a heating rate of $10^{\circ} \mathrm{C} / \mathrm{min}$. The decomposition of hydration products were observed and quantified [28]. The decomposition of $\mathrm{CH}$ is shown as follows:

$$
\mathrm{Ca}(\mathrm{OH})_{2} \stackrel{450^{\circ} \mathrm{C}}{\longrightarrow} \mathrm{CaO}+\mathrm{H}_{2} \mathrm{O} \uparrow
$$

According to this equation, the proportion of $\mathrm{CH}$ to the residual mass at $1000^{\circ} \mathrm{C}$ was determined as follows:

$$
m=\frac{74 \times m_{\text {loss }}}{18 \times m_{\text {remain }}} \times 100 \%
$$

where $m(\%)$ is the proportion of $\mathrm{CH}$ content to residual mass; $m_{\text {loss }}(\%)$ is the mass loss of samples at about $450^{\circ} \mathrm{C} ; m_{\text {remain }}(\%)$ is the residual mass after heating; 74 and 18 are the molar masses of $\mathrm{Ca}(\mathrm{OH})_{2}$ and $\mathrm{H}_{2} \mathrm{O}$, respectively.

\subsubsection{Pore structure measurement}

Mercury intrusion porosimetry (MIP) was used to measure the pore structure of hardened UHSC specimens. The mercury porosimeter is capable of generating up to $469 \mathrm{MPa}$ pressure and enabling the measurement of pores with apparent diameter of 3 to $380000 \mathrm{~nm}$ [41]. Samples for MIP testing were broken into $3.5-5.0 \mathrm{~mm}$ pieces and soaked in acetone to stop further hydration. They were then dried at $60^{\circ} \mathrm{C}$ in oven until constant mass. The measurements were carried out from the pressure of 0.2758 to $414 \mathrm{MPa}$. Glass tubes with the specimen and mercury were subsequently 
placed in low and high pressure analysis ports. Full-scan auto mode was selected with contact angle and surface tension of $140^{\circ}$ and $480 \mathrm{mN} / \mathrm{m}$, respectively. The intrusion mercury volume was recorded at each pressure point. The pore diameter is related to the applied pressure $\mathrm{P}$ using the Washburn equation as follows [29]:

$$
d=-\frac{4 \gamma \cos \theta}{P}
$$

where $d$ is the pore size; $\gamma$ is the surface tension of mercury $(0.485 \mathrm{~N} / \mathrm{m}) ; \theta$ is the contact angle between mercury and pore wall; $\mathrm{P}$ is the applied pressure. A volume-weighed mercury volume at a given pressure with the pore size could be evaluated from the equation.

\subsubsection{BSEM observation}

For the BSEM observation, samples of $15 \times 15 \times 15 \mathrm{~mm}$ with an embedded fiber were taken by cutting the dog-bone shaped specimens. The small samples were soaked in acetone to stop further hydration and then dried at $60^{\circ} \mathrm{C}$ in a vacuum oven until constant mass. They were grinded to obtain a relatively smooth surface, then mounted in epoxy resin and subjected to further grinding and polishing to ensure high smooth surface quality. The polished samples were then coated with gold and examined using a Hetachi S4700-SEM with the back-scattered detector in high vacuum mode. All images with the embedded fiber were taken at 250 magnification, and the resolution was set to $2560 \times 1920$.

\subsubsection{Micro-hardness measurement}

Micro-indention is based on applying a static load for a known period of time and measuring the response in terms of size of indentation. In this study, a $498 \mathrm{mN}$ load was applied on the samples for 
10 s. Points within 0 to $200 \mu \mathrm{m}$ distance from the fiber edge was measured. During the indention process, areas with sand were avoided. The micro-hardness or Vickers hardness (HV) was captured during the measurement. The average value of four indentations was reported.

\section{Results and discussion}

\subsection{Effect of silica fume content on flowability of fresh UHSC}

The variation of mini slump flow of UHSCs mixture with different silica fume contents is given in Fig. 3. It was observed that, for U0 mixture without any silica fume, the slump flow of mixture was only $113 \mathrm{~mm}$. With the incorporation of $10 \%$ and $15 \%$ silica fume, the slump flow increased to 150 and $175 \mathrm{~mm}$, respectively. However, further increase in silica fume content decreased the flowability. The mini slump flow of UHSC with $25 \%$ silica fume (U25) decreased to $165 \mathrm{~mm}$. Moreover, during the experiment, it was found that the time for U25 to obtain flowability was prolonged compared to other mixtures. When $30 \%$ silica fume was incorporated, no flowability was observed. The improvement in slump flow for the mixtures with silica fume content up to $20 \%$ can be attributed to the lubrication effect of fine silica fume, which released some of the entrapped water between small particles, and hence increased flowability. However, high silica fume content decreased the flowability due to its high surface area [24].

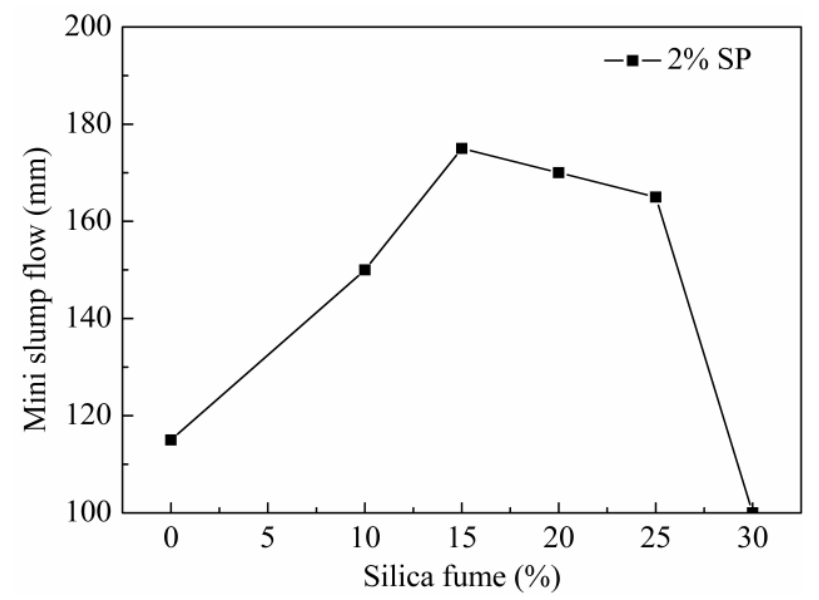


Fig. 3 Mini slump flow of UHSCs with different silica fume contents

\subsection{Effect of silica fume content on heat of hydration of UHSC}

Figure 4 shows the rate of heat evolution of UHSCs with and without silica fume. As can be seen from Fig. 4(a), compared to U0, the duration of dormant period of UHSCs containing silica fume decreased from 12 to $9 \mathrm{~h}$ or less. As hydration proceeded, U25 samples first showed the accelerated hydration peak, followed by U20, U15, and U10. However, the accelerated hydration peak of U0 was delayed to $28 \mathrm{~h}$. As illustrated in Fig. 4(b), the heat of hydration of UHSCs mixture incorporated with silica fume evolved quickly, and the heat generation was faster than that of the reference sample U0. This is because, on the first contact of cement with water, $\mathrm{Ca}^{2+}$ and $\mathrm{OH}^{-}$ions are rapidly released from the surface of cement particles. When silica fume is incorporated, the dissolution of $\mathrm{SiO}_{4}{ }^{4-}$ ion can absorb $\mathrm{Ca}^{2+}$ and $\mathrm{OH}^{-}$ions to form calcium silicate hydrate $(\mathrm{C}-\mathrm{S}-\mathrm{H})$, which increases the rate of heat and amount of heat evolution [30].

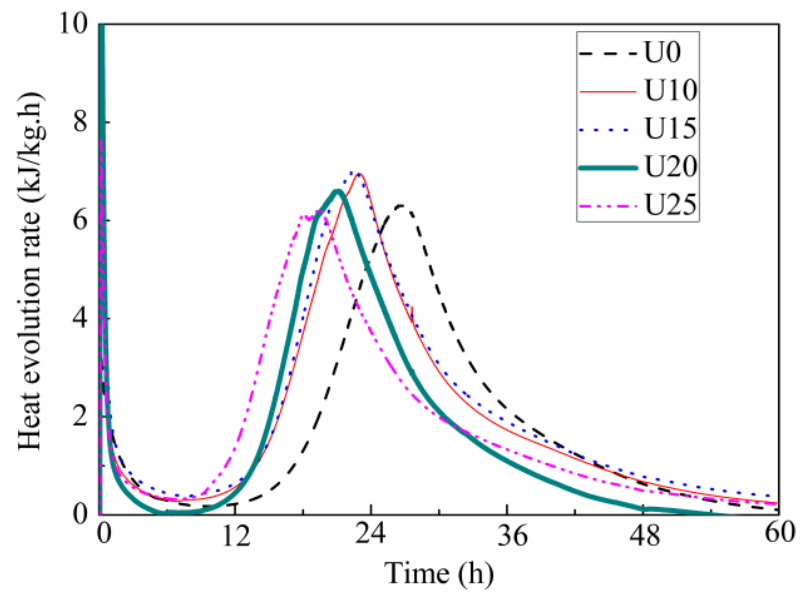

(a) Heat evolution rate

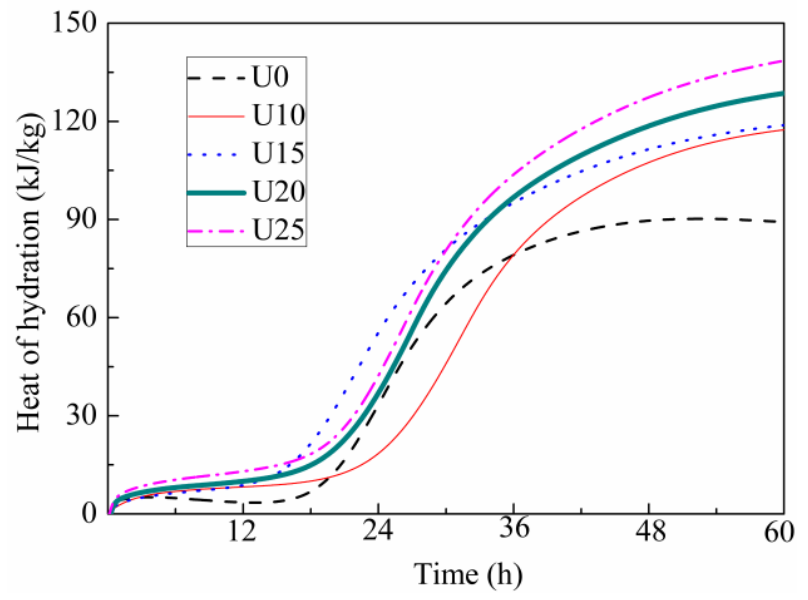

(b) Total heat of hydration

Fig. 4 Heat evolution rate of UHSCs with different silica fume contents

\subsection{Effect of silica fume content on compressive and flexural strengths of UHSC}

The influences of silica fume content on compressive and flexural strengths of UHSCs are 
compared in Fig. 5. The silica fume content had a significant effect on compressive and flexural strengths at early ages up to $7 \mathrm{~d}$. After $7 \mathrm{~d}$, the increase in compressive strength was only about $11 \%$. For the flexural strength, it increased significantly from 1 to $3 \mathrm{~d}$. However, it remained almost the same afterward. It should be note that for U0, U20, and U25, the flexural strengths at $91 \mathrm{~d}$ slightly decreased when compared to that at $28 \mathrm{~d}$. This may be due to the variation of testing.

Significant increase in strength was observed with the increase of silica fume replacement from 0 to $20 \%$. However, when silica fume exceeded $20 \%$, the strengths tended to decrease. The compressive and flexural strengths of U0 at $28 \mathrm{~d}$ were 89.8 and $19.1 \mathrm{MPa}$, respectively. When $10 \%$, $15 \%, 20 \%$, and $25 \%$ silica fume replacement were used, the compressive strength increased by approximately $18 \%, 16 \%, 28 \%$, and 25\%, respectively, as shown in Fig. 5(a). The flexural strength increased by approximately $11 \%, 15 \%, 29 \%$, and $18 \%$, respectively. The addition of $15 \%$ to $20 \%$ silica fume decreased the porosity and improved the strength due to its filling effect in addition to the pozzolanic reaction [31]. However, a high content of $25 \%$ silica fume increased plastic viscosity and yield stress, which could result in air entrapment [31]. Furthermore, high silica fume content could significantly increase the risk of micro-cracking due to autogenous shrinkage, which could affect mechanical properties [32,33].

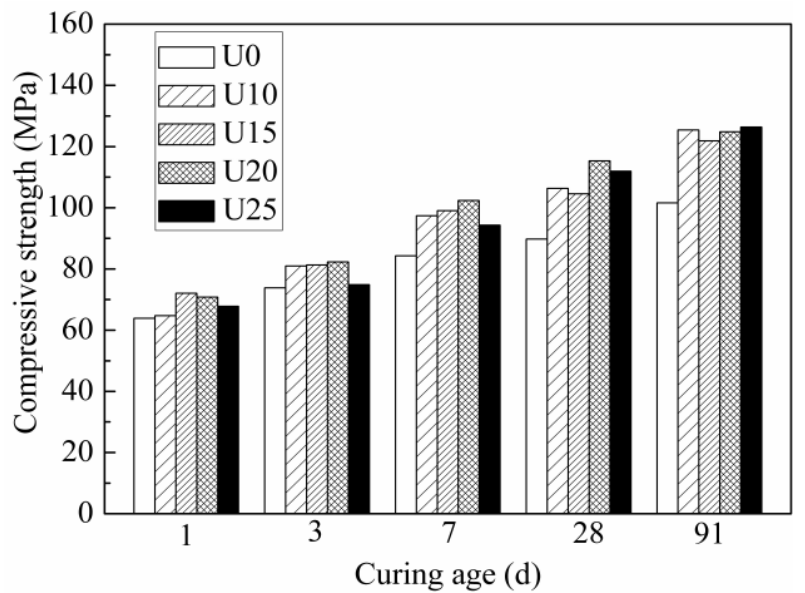

(a) Compressive strength

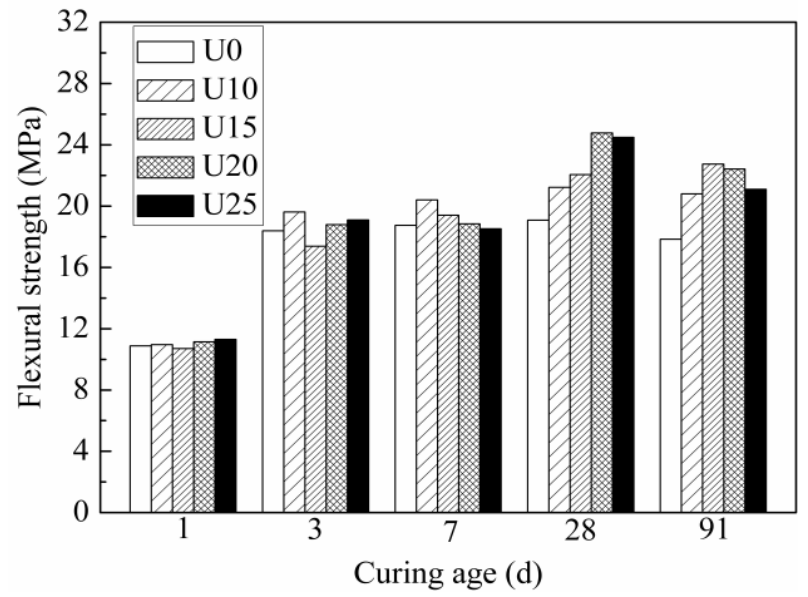

(b) Flexural strength 
Fig. 5 Effect of silica fume content on compressive and flexural strengths of UHSCs mixture

\subsection{TG/DTG analyses}

The TG and DTG results of UHSCs with different silica fume contents at $28 \mathrm{~d}$ are shown in Fig.

6. It is obvious that all the samples showed mass losses in the temperature ranges of $30-200^{\circ} \mathrm{C}$, $370-470^{\circ} \mathrm{C}$, and $600-730^{\circ} \mathrm{C}$. Mass loss between 30 and $200^{\circ} \mathrm{C}$ can be attributed to the loss of combined water initially from C-S-H $\left(80-90^{\circ} \mathrm{C}\right)$ and then from ettringite $\left(\sim 130^{\circ} \mathrm{C}\right)$ [34]. Mass loss in the range of $370-470^{\circ} \mathrm{C}$ is due to the decomposition of $\mathrm{CH}$ [35]. From Fig. 6(a), it can be found that UHSC samples containing $15 \%-25 \%$ silica fume showed a larger mass loss in the range of $30-200^{\circ} \mathrm{C}$, but a smaller mass loss from 370 to $470^{\circ} \mathrm{C}$, compared to U0. Additionally, the peak intensity of C-S-H was sharper than that of U0, as seen from Fig. 6(b). These results indicated that pozzolanic reaction increased with the increase of silica fume content. As the temperature increased from 600 to $730^{\circ} \mathrm{C}$, the mass loss decreased further. This can be associated with the decomposition of calcium carbonate resulting from the carbonation of hydration products with $\mathrm{CO}_{2}$ from air during sample preparation [36].

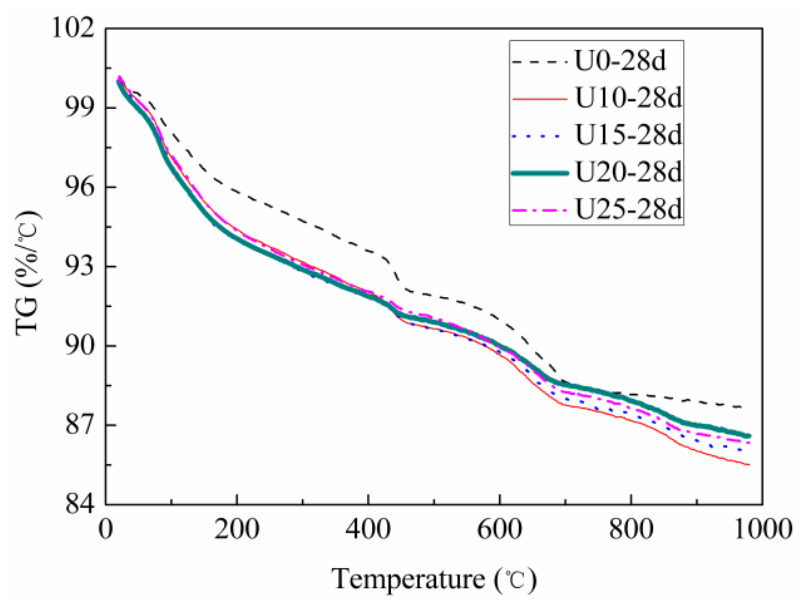

(a) TG curves

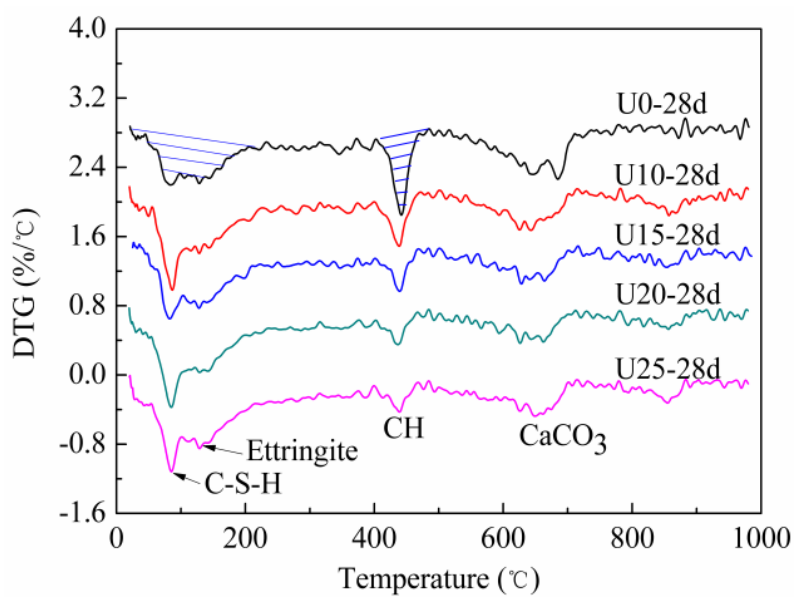

(b) DTG curves

Fig. 6 TG and DTG curves of UHSCs mixture with different silica fume contents at $28 \mathrm{~d}$ 
Figure 7 shows the effects of curing time on TG and DTG curves of UHSCs with $15 \%$ and $20 \%$ silica fume. With the increase of curing time, the mass loss between 30 and $200^{\circ} \mathrm{C}$ increased, as can be seen from Fig. 7 (b) and (d). Moreover, an obvious $\mathrm{C}-\mathrm{S}-\mathrm{H}$ peak at $80-90^{\circ} \mathrm{C}$ with high intensity first appeared at $7 \mathrm{~d}$. This suggested that hydration products of $\mathrm{C}-\mathrm{S}-\mathrm{H}$ and/or ettringite phase in the $\mathrm{U} 15$ and $\mathrm{U} 20$ increased with curing time. Besides, the mass loss in the range of $370-470^{\circ} \mathrm{C}$ decreased with curing age, which indicated reduced $\mathrm{CH}$ content. A relatively weak endothermic peak of $\mathrm{CH}$ for the samples at $91 \mathrm{~d}$ was observed. Therefore, it is reasonable that $\mathrm{CH}$ was gradually consumed by pozzolanic reaction with silica fume to from $\mathrm{C}-\mathrm{S}-\mathrm{H}$, which dominated the performance of UHSC [37].

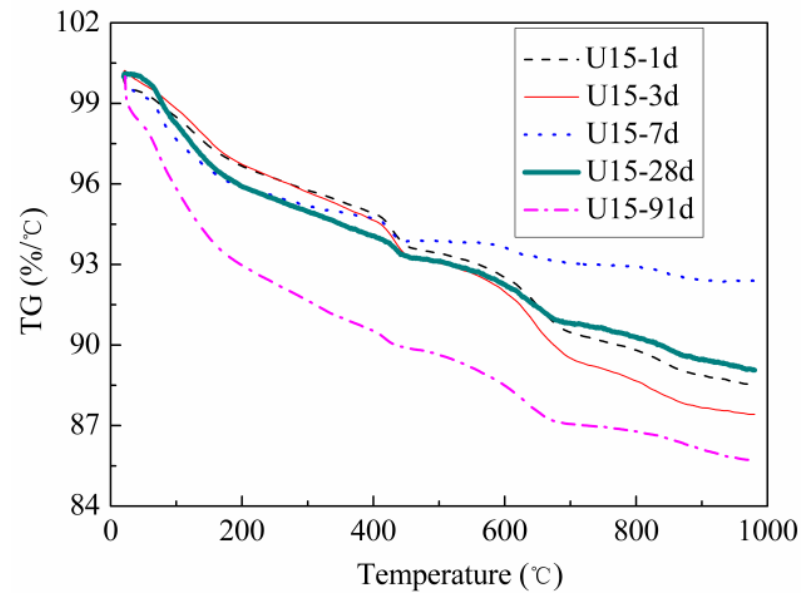

(a) TG curves of U15

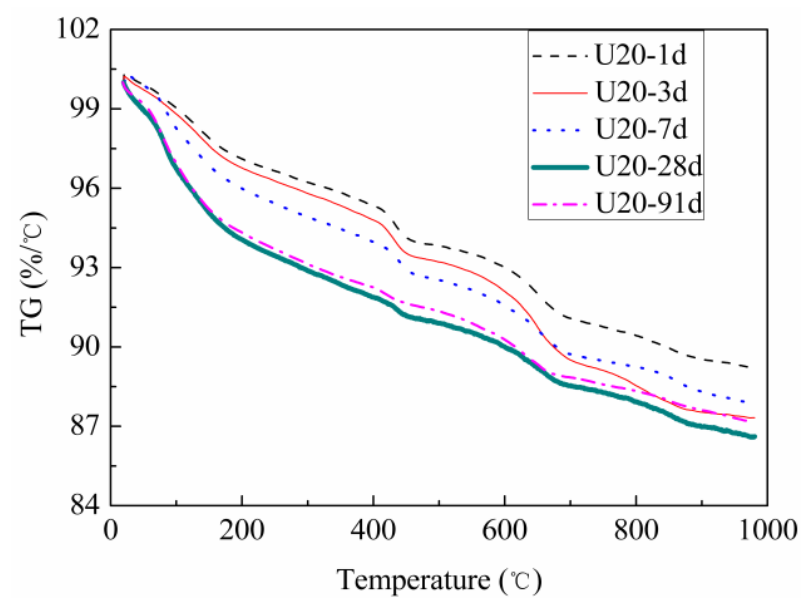

(c) TG curves of U20

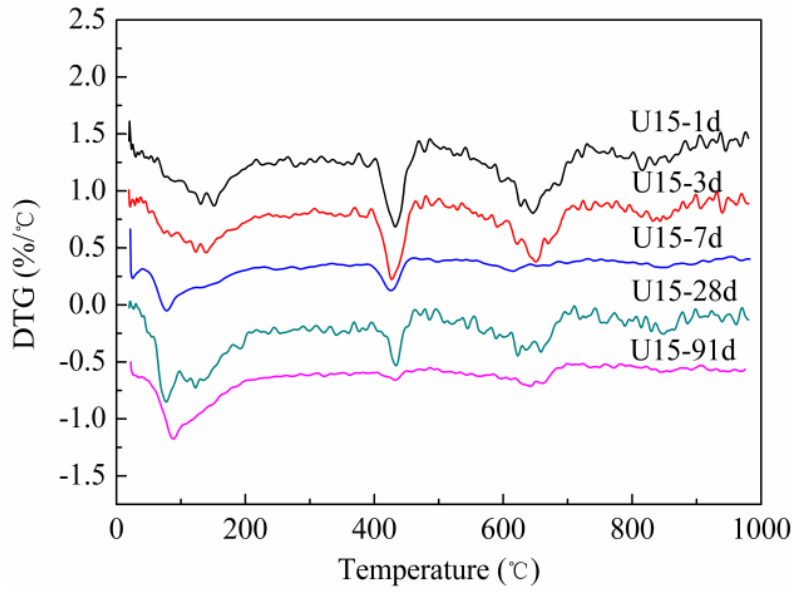

(b) DTG curves of U15

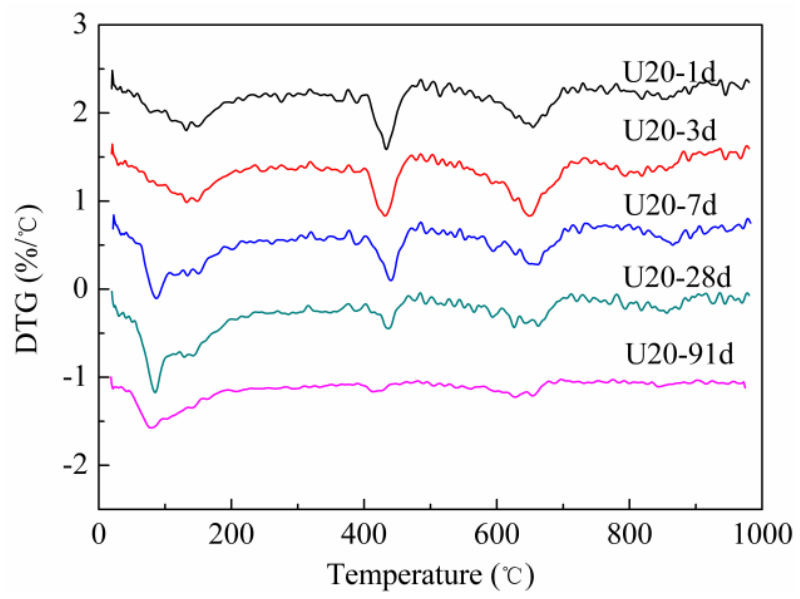

(d) DTG curves of U20

Fig. 7 TG and DTG curves of U15 and U20 samples at different curing ages 
The $\mathrm{CH}$ content of UHSCs at different ages is plotted in Fig. 8. It can be seen that the $\mathrm{CH}$ content decreased with both the incorporation of silica fume and prolongation of age. The reference batch U0 had a constant $\mathrm{CH}$ content of around $6 \%$ regardless of the age. However, it reduced gradually with the increase of silica fume content. U15, U20, and U25 had an obvious lower $\mathrm{CH}$ contents compared with U0. It can be also seen from Fig. 8 that no significant difference was observed for the samples at 1 and $3 \mathrm{~d}$. However, the $\mathrm{CH}$ content of U15, U20, and U25 at $28 \mathrm{~d}$ was about $3 \%$ only, which was about $50 \%$ lower than that at $1 \mathrm{~d}$. At $91 \mathrm{~d}$, the CH content of U15, U20, and U25 were reduced further to $2.3 \%$. This indicated that silica fume could efficiently react with $\mathrm{CH}$ to form C-S-H due to pozzolanic reaction, and thus improved the strengths of UHSC.

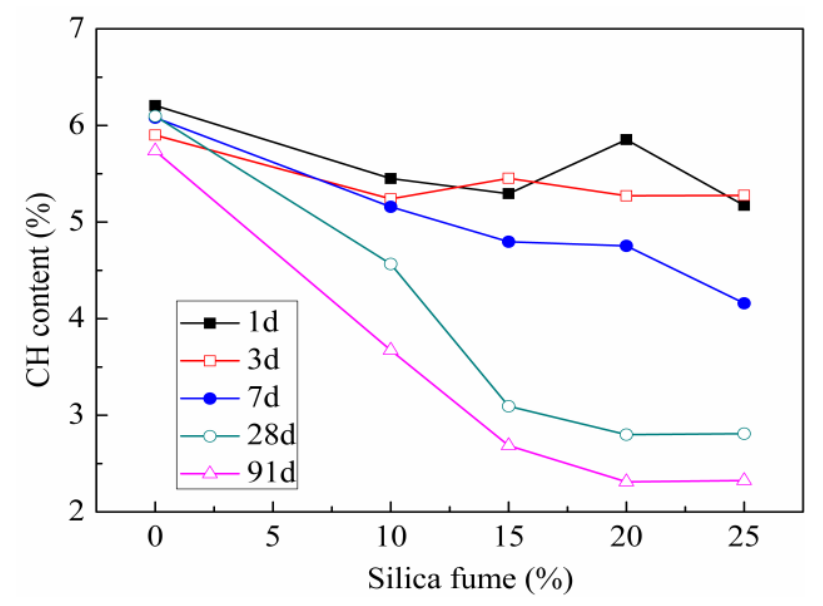

Fig. 8 Content of $\mathrm{CH}$ in UHSCs from TG analyses

\subsection{Pore structure characteristics}

Figure 9 shows the effect of silica fume content on pore structure of UHSCs at 1 and $28 \mathrm{~d}$, which covers the pore size range from around $5 \mathrm{~nm}$ to $200 \mu \mathrm{m}$. It can be seen from Fig. 9 (a) and (b) that UHSCs incorporating silica fume at $1 \mathrm{~d}$ had slightly lower porosity and peak value at dv/dlog (d) curves compared to U0. It is suggested that the most probable pore diameters, corresponding to the peak value in $d v / d \log (d)$ curves, are strongly correlate with the permeability and ion diffusivity in 
cement-based materials [38]. When the curing age was prolonged to $28 \mathrm{~d}$, it became apparent that a very low porosity of $6 \%-8 \%$ was observed for UHSCs with $15 \%-25 \%$ silica fume. This corresponds to a reduction of $67 \%$ in comparison to that of $\mathrm{U} 0$ and $\mathrm{U} 10$.

It can also be noted that the U25 had a higher porosity than that of U20. This is consistent with the reduced flowability and strength. Besides, the most probable pore diameters decreased gradually with the increase of silica fume content, with the dv/dlog (d) curves shifted left to reflect pore refinement. Therefore, the incorporation of $15 \%-25 \%$ silica fume significantly densified the microstructure of UHPCs due to the combined filling and pozzolanic effects [39].

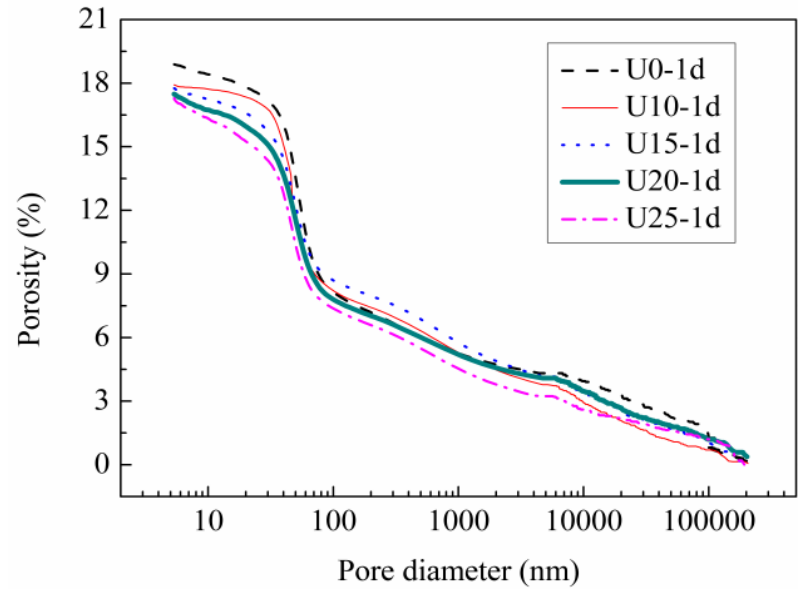

(a) Cumulative porosity at $1 \mathrm{~d}$

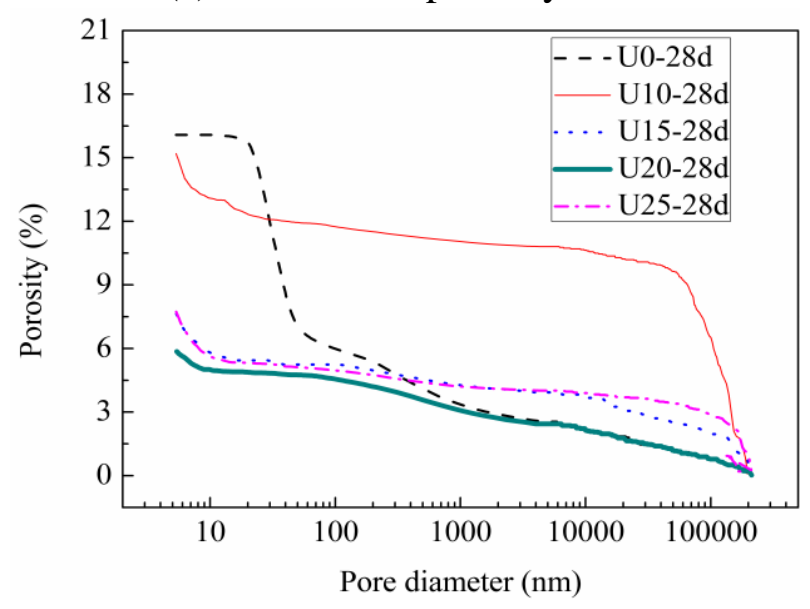

(c) Cumulative porosity at $28 \mathrm{~d}$

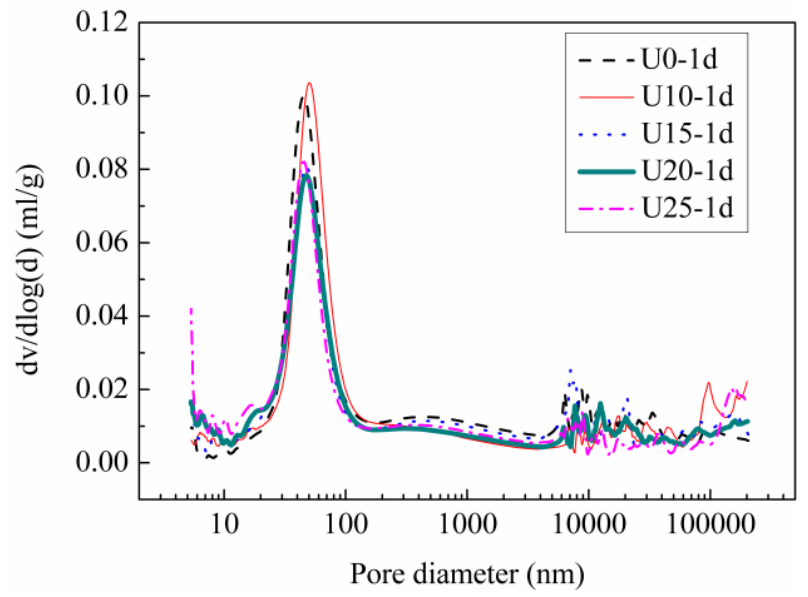

(b) Differential pore size distribution at $1 \mathrm{~d}$

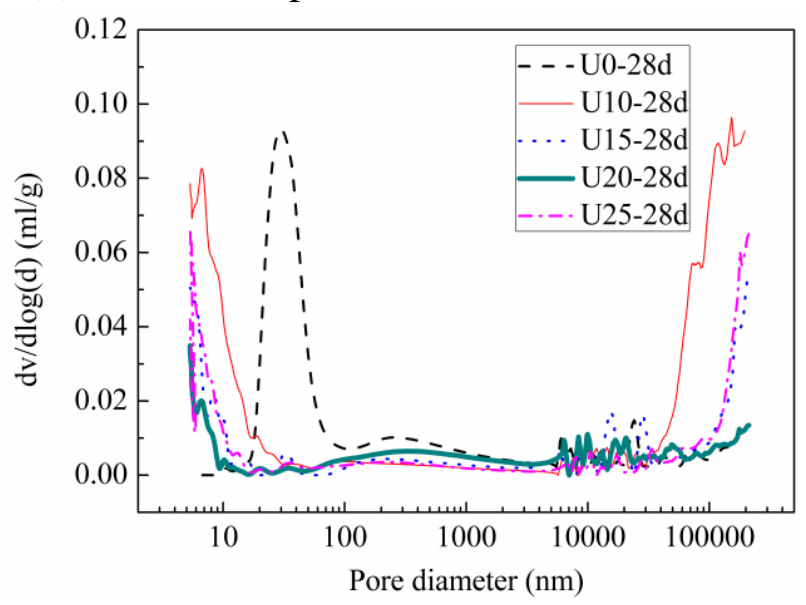

(d) Differential pore size distribution at $28 \mathrm{~d}$

Fig. 9 Pore structure of UHSCs with different silica fume contents at 1 and $28 \mathrm{~d}$

Figure 10 shows the effects of the curing age on pore structure of the U20. As seen from Fig. 
10(a), the porosity at $1 \mathrm{~d}$ was $17.5 \%$. However, at curing ages of 3,7 , and $28 \mathrm{~d}$, the porosity was reduced to $11 \%, 9 \%$, and $6 \%$, respectively. At $91 \mathrm{~d}$, the porosity was similar to that at $28 \mathrm{~d}$. This is consistent with that strengths of UHSC increased with curing time. The most probable pore diameters decreased from 20 to $7 \mathrm{~nm}$, as shown in Fig. 10(b), which corresponded to the pore refinement with the increase of curing age.
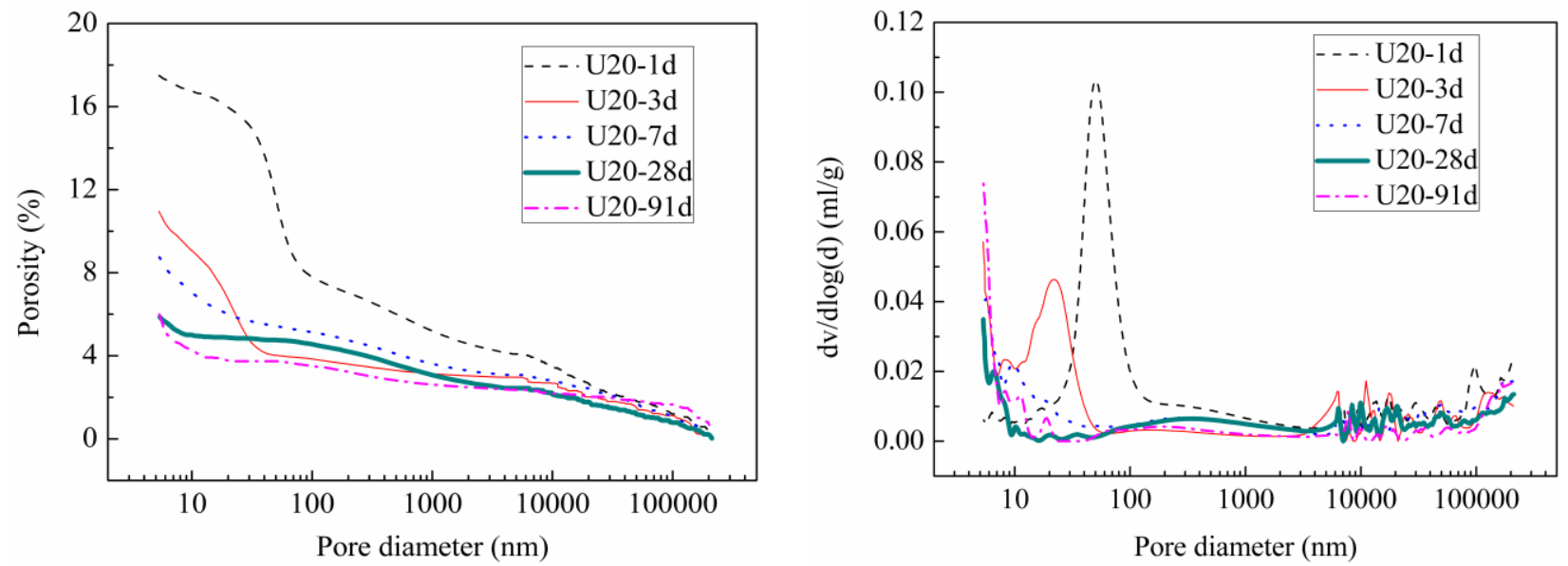

(a) Cumulative porosity at different ages (b) Differential pore size distribution at different ages Fig. 10 Pore structure of U20 mixture at different ages

The measured pores can be divided into five size ranges, including gel micro-pores with appeared diameter $<10 \mathrm{~nm}$, meso-pores of $10-50 \mathrm{~nm}$, middle capillary pores of $50-100 \mathrm{~nm}$, large capillary pores of $100 \mathrm{~nm}-5 \mu \mathrm{m}$ and macro-pore $>5 \mu \mathrm{m}[40,41]$. The change in pore size distribution of UHSC with silica fume content and curing age are shown in Fig. 11. As can be seen from Fig. 11(a), the volume fraction of gel pores increased with the incorporation of silica fume although the difference was limited. It changed significantly with silica fume content at $28 \mathrm{~d}$, as shown in Fig. 10(b). Compared with the U0, the proportion of gel micro-pores of the samples with silica fume increased from $0.02 \%$ to $25 \%$, while the meso-pores reduced from $55 \%$ to $6 \%$. It was reported that the nano-pores with diameter finer than $10 \mathrm{~nm}$ corresponded typically to gel pores in $\mathrm{C}-\mathrm{S}-\mathrm{H}$ with water held by hydrogen bond [42]. These pores mainly affect shrinkage and creep of the hardened 
cement-based materials. It can be also note from Fig. 11(b) that the total capillary pores (meso-pores, middle and large capillary pores) of UHSC with silica fume decreased considerably. Capillary pores larger than $50 \mathrm{~nm}$ can have great influence on mechanical properties and permeability of cement-based materials [40]. This is in good agreement with the results concerning significantly enhancement in the mechanical behavior of UHSC with silica fume.

The volume of macro-pores also increased. Such macro-pores include entrapped (1-3 mm) and entrained air bubbles $(50-200 \mu \mathrm{m})$, which are often exhibited as discrete, individual bubbles with spherical shape in concrete [41]. The increased volume of macro-pores may be due to air entrapment associated with reduced workability of UHSCs with increased silica fume content [40]. The evolution of pore structure of the U20 mixture with increased curing age can be seen from Fig. 11(c). It is interesting to note that the volume fraction of gel micro-pores of samples at $1 \mathrm{~d}$ was $4.7 \%$. However, such volume of gel micro-pores increased from $4.7 \%$ to $26 \%$, while the total capillary pores decreased from $72 \%$ to $30 \%$ when curing age was prolonged from 1 to $91 \mathrm{~d}$. In addition, the volume of meso-pores and middle capillary pores were reduced to very small portions.

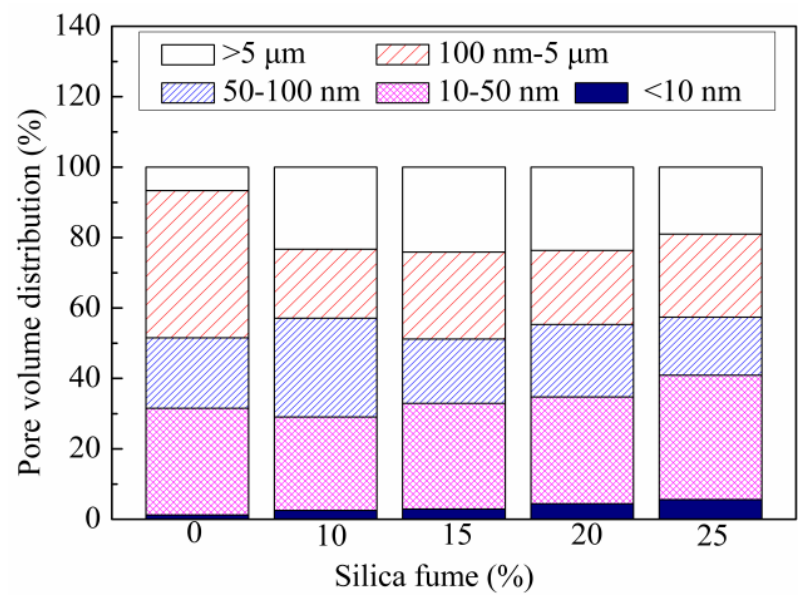

(a) UHSC with different silica fume at $1 \mathrm{~d}$

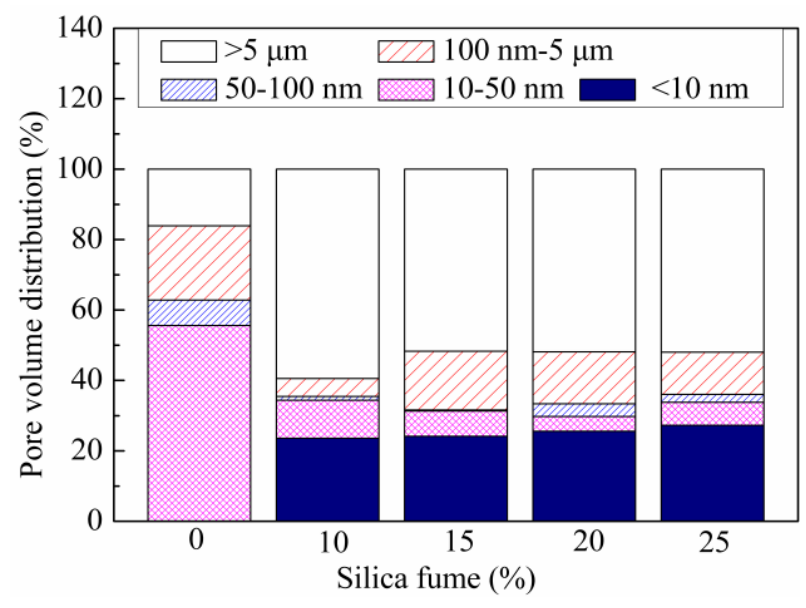

(b) UHSC with different silica fume at $28 \mathrm{~d}$ 


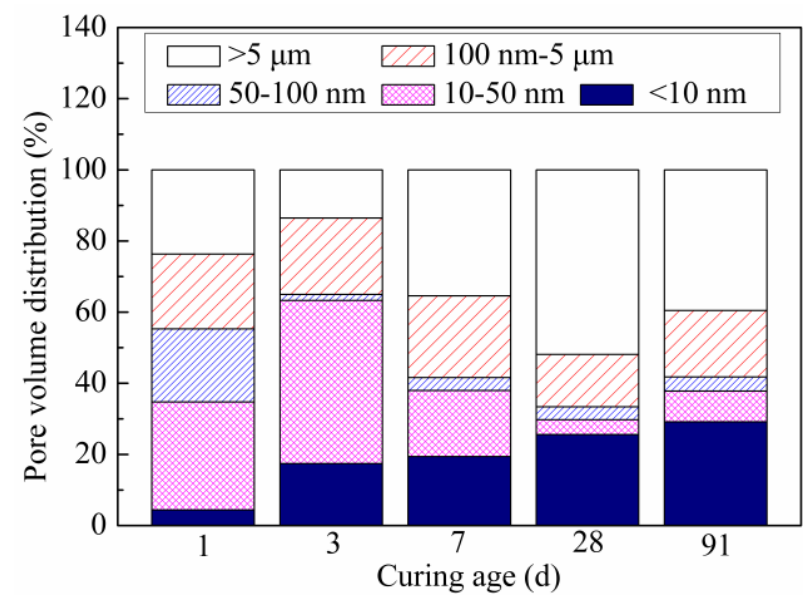

(c) U20 at different curing ages

Fig. 11 Pore volume distribution of UHSCs

3.6. Effect of silica fume content on bond properties between fiber and matrix

\subsubsection{Fiber pullout load-slip relationship}

The effect of silica fume content on pullout load-slip curves of UHSCs at 1, 3, 7, 28, and $91 \mathrm{~d}$ is shown in Fig. 12. Generally, the pullout behavior can be divided into four distinct regions, including well bonded region, partially debonded region, fully debonded region, and removal of fiber $[43,44]$. At the well bonded region, within a pullout slip of about $1.2 \mathrm{~mm}$, the pullout load-slip behavior was observed to be linear elastic properties. When peak load was achieved, it remained almost stable when the pullout slip increased from 1.2 to $3.2 \mathrm{~mm}$. This suggested slip-hardening behavior because of higher matrix packing density around the fiber due to high frictional coefficient and fiber surface pressure [4]. In this range, the load-slip curve did not show obvious descending load, but a part of the fiber had already debonded from the UHSC matrix. With continued loading, the fiber was gradually pulled out from the matrix. Once fiber fully debonded from matrix, the pullout behavior is governed by frictional bond shear stress with the interface and gradually pulled out from matrix. On the other hand, it can be seen from Fig. 12 that UHSC mixtures with silica fume led to obvious increase in both pullout peak load and stress-slip response in comparison to the U0. Although $10 \%$ silica fume 
contributed little enhancement to pullout load of UHSC, when the dosage ranged from $15 \%-25 \%$, the peak load and slip-hardening behavior was significantly improved.

The curing age also contributed a lot to the pullout behavior of UHSCs. There was little increase in peak load from 1 to $3 \mathrm{~d}$. However, when the curing age was increased from 3 to $7 \mathrm{~d}$, the peak load for UHSCs containing $15 \%$ to $20 \%$ silica fume increased from 20 to $30 \mathrm{~N}$. With the curing age increased from 7 to $28 \mathrm{~d}$, a considerable enhancement was observed with peak load increase from 30 to $40 \mathrm{~N}$. At $91 \mathrm{~d}$, the pullout load increased a little but the curves of U20 and U25 showed enhanced slip-hardening behavior. Therefore, approximately $28 \mathrm{~d}$ of curing resulted in comparatively good interfacial bond properties. However, this is different from the results obtained by Chan and Li [45], in which no significant gain in bond strength was observed after $7 \mathrm{~d}$. This may be due to different raw materials and mixture proportions used in the two studies. It was shown that both maximum pull-out load and total pullout energy increased with increasing matrix strength of very-high strength concrete composites [19]. The compressive strengths of UHSC matrix made with different silica fume contents increased by about 10\%-20\% from 7 to $28 \mathrm{~d}$, which resulted in corresponding enhanced pullout bond behavior.

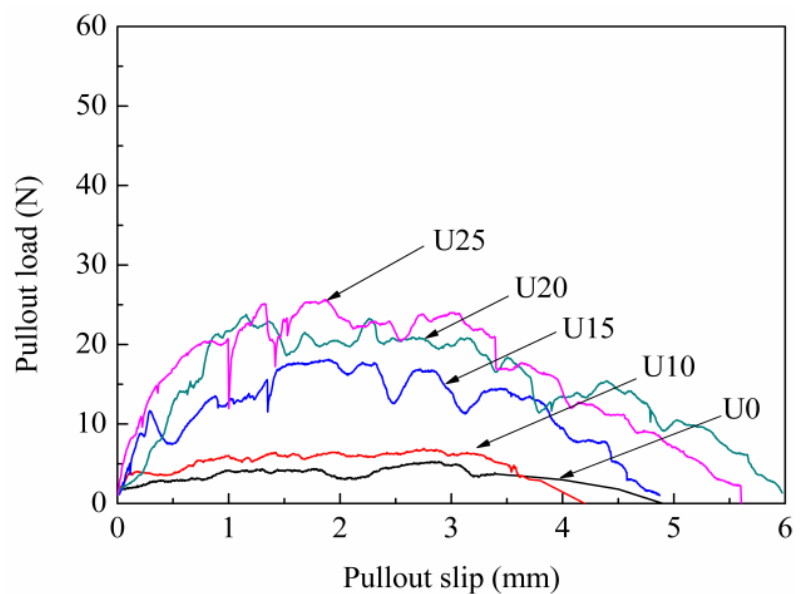

(a) $1 \mathrm{~d}$

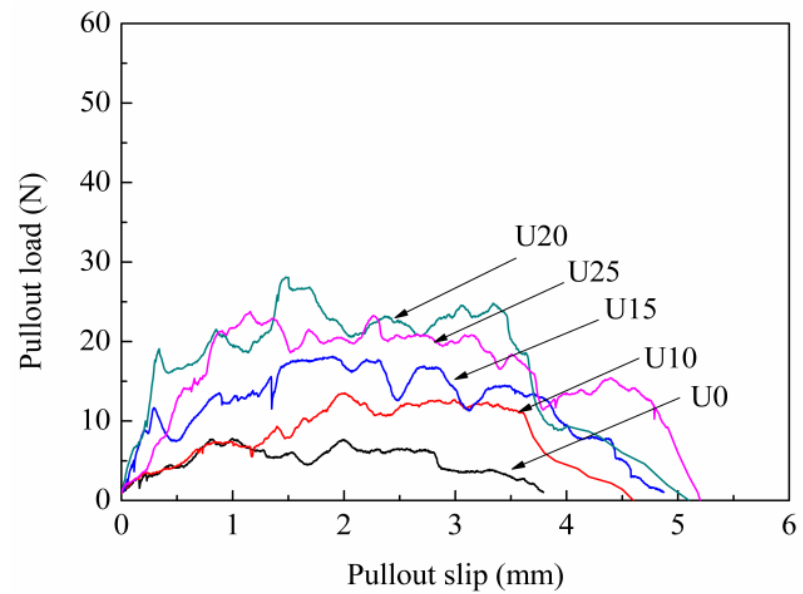

(b) $3 \mathrm{~d}$ 


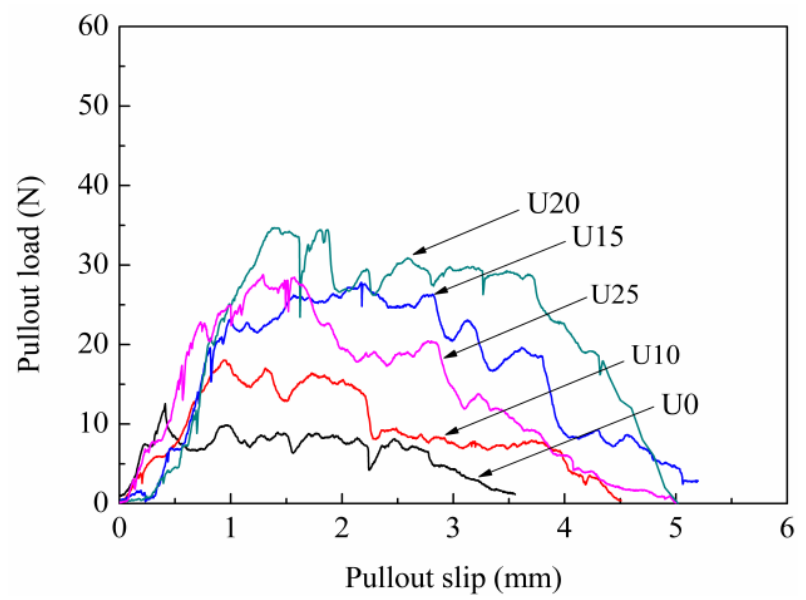

(c) $7 \mathrm{~d}$

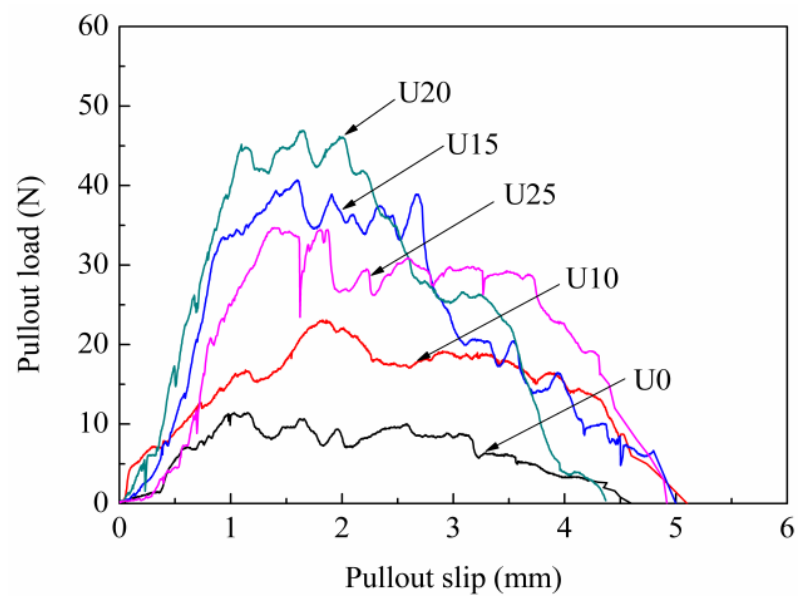

(d) $28 \mathrm{~d}$

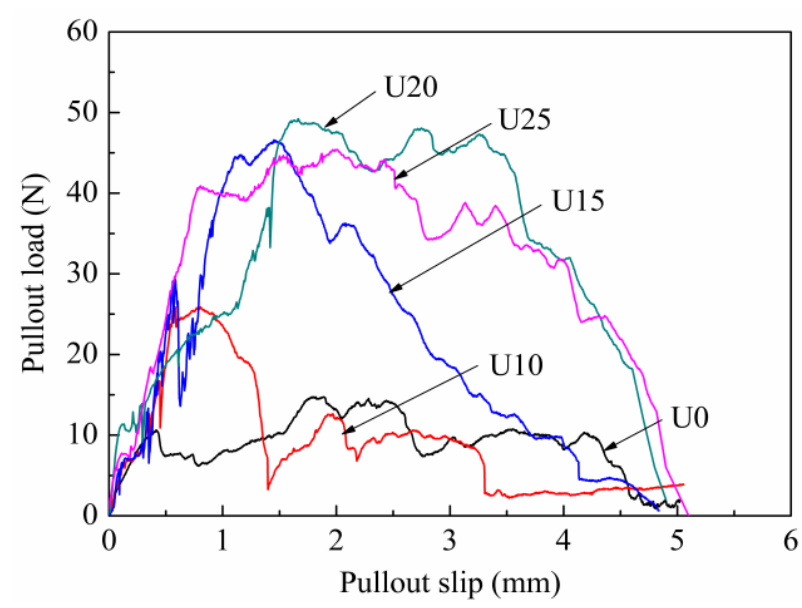

(d) $91 \mathrm{~d}$

Fig. 12 Effect of silica fume content on pullout load-slip curves of UHSCs

\subsubsection{Bond strength}

Figure 13 shows the change in bond strength of UHSCs with different silica fume contents at 1 , $3,7,28$, and $91 \mathrm{~d}$. It can be found that the bond strength increased with the incorporation of silica fume. For U0, the bond strength was only 1.12 MPa regardless of the curing age. This is consistent with the TG results that the $\mathrm{CH}$ content did not vary considerable with curing age up to $91 \mathrm{~d}$. With the incorporation of silica fume, the bond strength significantly increased with curing age. For U10, the $28 \mathrm{~d}$ bonding strength increased to $2.2 \mathrm{MPa}$. When silica fume content reached $15 \%-25 \%$, the bond strength remained at about $3 \mathrm{MPa}$, which increased by $168 \%$ compared to U0 sample. The optimum silica fume content for bond strength was between $15 \%$ and $25 \%$. Chan [22] found that the 
optimum dosage of silica fume content for reactive powder concrete was between $20 \%$ and $30 \%$ by the mass of cement. In this research, $15 \%$ to $25 \%$ silica fume by mass of binder equals to $17.6 \%$ to $33 \%$ by mass of cement. The difference is that the bond strength obtained by Chan was as high as 4.8-5.5 $\mathrm{MPa}$ [22]. This was mainly attributed to heat curing. The average $\mathrm{C}-\mathrm{S}-\mathrm{H}$ chain at $20^{\circ} \mathrm{C}$ curing was shorter than that under heat curing, which leaded to lower bond strength $[46,47]$.

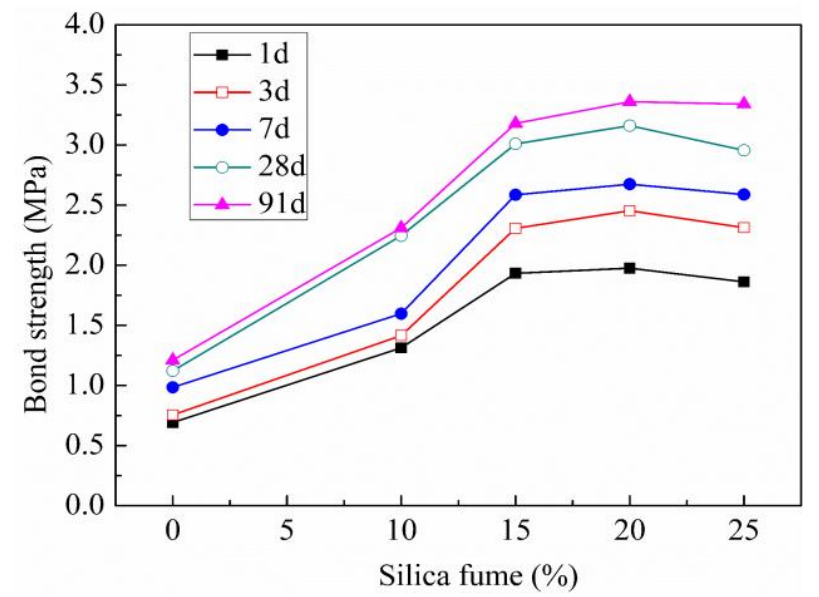

Fig. 13 Effect of silica fume on fiber bond strength of UHSCs at different ages

\subsubsection{Pullout energy}

Pullout energy is the mechanical energy consumed during fiber pullout testing, which can be obtained by integrating the area under pullout load-slip curves. Fig. 14 shows the effects of silica fume content on pullout energy of UHSC at 7 and $28 \mathrm{~d}$. It is obvious that the pullout energy increased with the increase of silica fume content. The pullout energy of the samples with $15 \%-25 \%$ silica fume at $28 \mathrm{~d}$ was $120 \mathrm{~N}$-mm, which had an increase of about $250 \%$ when compared to the U0. Besides, UHSC samples with $15 \%-25 \%$ silica fume had a more significant improvement in pullout energy as the rate of bond strength increase slowed down. 


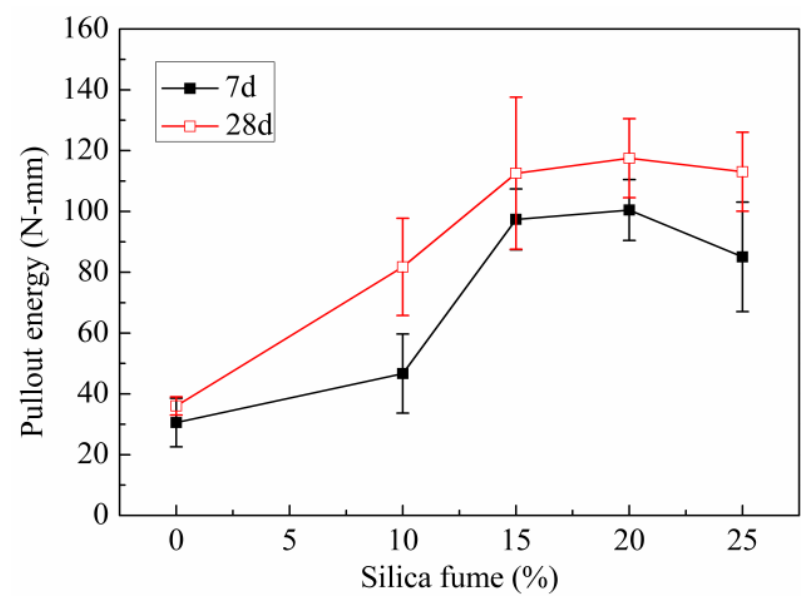

Fig. 14 Effect of silica fume content on pullout energy of UHSCs

\subsubsection{Microstructural analysis for ITZ around fiber}

Figure 15 shows the microstructure around fiber in U20 at 1 and $28 \mathrm{~d}$. A relatively large porous zone can be observed in the zone located within $50 \mu \mathrm{m}$ from the fiber edge. This weak zone can reduce the contact area of fiber to matrix. Besides, less unhydrated cement and smaller porous areas in U20 at $28 \mathrm{~d}$ were observed both around the embedded fiber and in the bulk mortar compared with that at $1 \mathrm{~d}$. This agrees well with the porosity measured by MIP. Prolongation of curing age ensures denser microstructure and higher degree of hydration around fiber, and hence better bond properties.

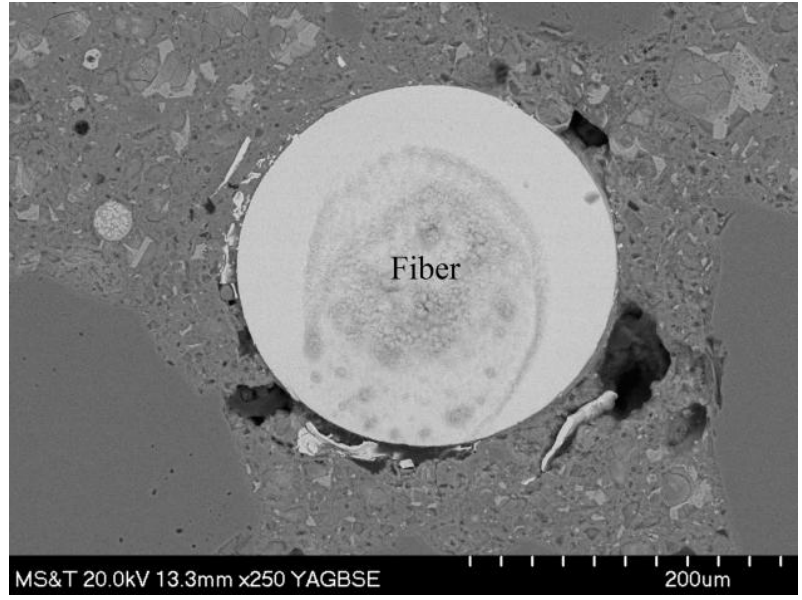

(a) U20 at $1 \mathrm{~d}$

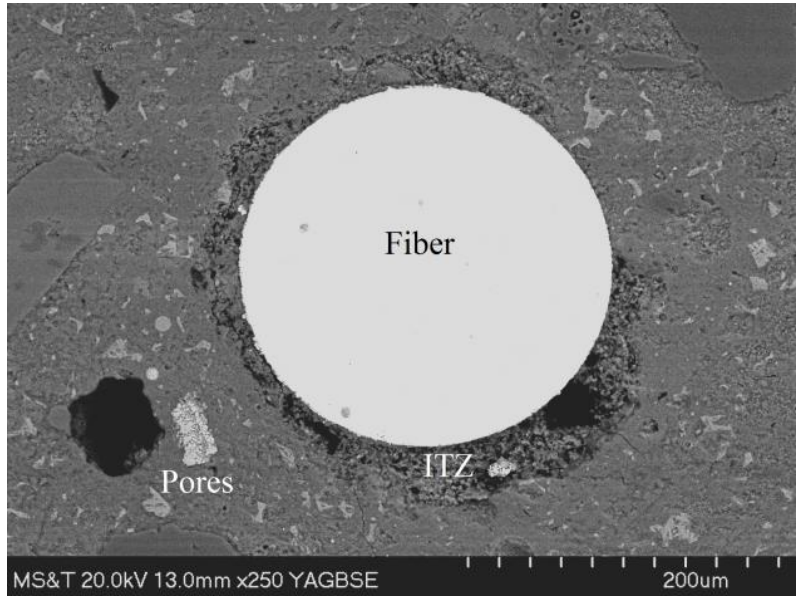

(b) U20 at $28 \mathrm{~d}$

Fig. 15 BSEM images of U20 samples with an embedded fiber

The micro-hardness of matrix with different distances to fiber edge is indicated in Table 3 . The 
micro-hardness within $80 \mu \mathrm{m}$ was obviously lower than that with far distance. Besides, UHSC with $20 \%$ silica fume had higher micro-hardness than that of the reference batch. This suggested high strength hydration products for UHSCs with silica fume.

Table 3 Micro-hardness of matrix around fiber

\begin{tabular}{cccc}
\hline \multirow{2}{*}{ No. } & \multicolumn{3}{c}{ Micro-hardness (HV) } \\
\cline { 2 - 4 } & U20-1d & U20-28d & U0-28d \\
\hline $40 \mu \mathrm{m}$ & 61.15 & 103.95 & 85.00 \\
$80 \mu \mathrm{m}$ & 85.01 & 110.33 & 97.28 \\
$120 \mu \mathrm{m}$ & 103.73 & 140.20 & 127.20 \\
$160 \mu \mathrm{m}$ & 115.85 & 140.30 & 131.03 \\
$200 \mu \mathrm{m}$ & 95.95 & 145.00 & 135.50 \\
$240 \mu \mathrm{m}$ & 112.85 & 133.80 & 133.80 \\
\hline
\end{tabular}

The characteristic of crystal enrichment, orientation of $\mathrm{CH}$, and presence of great concentration of micro-cracks and pores are the main reasons for the poor quality of the interface between cement paste and aggregate, reinforcing bars, or fiber inclusions [6]. In terms of TG and MIP results, UHSCs incorporation of $15 \%-25 \%$ silica fume had a lower $\mathrm{CH}$ content and porosity, and a higher amount of C-S-H than the U0 mixture did. This suggests that silica fume effectively reacted with $\mathrm{CH}$ to form $\mathrm{C}-\mathrm{S}-\mathrm{H}$, which contributes to reduction in some of the weaken features in the ITZ, enhancement in strength of the matrix, and improvement in interface bond [48]. Moreover, incorporation of silica fume can resulted in high strength hydration products, as indicated by micro-hardness test. Thus, $15 \%-25 \%$ silica fume content seems to be sufficient to enhance the microstructure of the interface between steel fibers and matrix, and hence the bond to fiber characteristics.

\section{Discussion}

The results above shows that the flowability, compressive and flexural strengths, microstructure, 
and bond to steel fiber in UHSCs with different silica fume contents are closely related to each other. Because of highly fine particle size and high $\mathrm{SiO}_{2}$ content of silica fume, the incorporation of silica fume can reduce the porosity, refine the pores, and increase the $\mathrm{C}-\mathrm{S}-\mathrm{H}$ content. The lower the porosity is, the higher the cement packing density in the bulk matrix and ITZ is $[19,41]$. Therefore, a greater content of the high strength cement hydration products, such as $\mathrm{C}-\mathrm{S}-\mathrm{H}$, are necessary to ensure high compressive and flexural strengths. This can enhance stress transferring between fiber and matrix.

Additionally, silica fume could significantly increase the autogenous shrinkage, especially in the UHSC with low w/b and high cementitious materials content [49]. Generally, the higher the amount of silica fume is, the larger the autogenous shrinkage is. The autogenous shrinkage is controlled mainly by the size of the pores smaller than $10 \mathrm{~nm}$ [50]. It is obvious that the volume fraction of those pores increased with the increase of silica fume content, as described in Section 3.5. Although autogenous shrinkage can lead to cracking of the cement paste, in UHSC it can exert some prestressing effect on fiber-matrix interface and eventually lead to increased bond to fiber. However, when the silica fume content exceeds a certain value, workability was reduced and the greater viscosity led to some entrapment of air bubbles [31]. This can reduce the quality of the matrix and interface, and thus reduce compressive and flexural strengths and bond properties.

\section{Conclusions}

Based on the results from this study, the following conclusions can be drawn:

(1) Due to the accelerated hydration of cement by silica fume, the compressive and flexural strengths of UHSCs matrix containing 15\%-25\% silica fume were enhanced by 10-25 MPa after $28 \mathrm{~d}$ 
when compared to that of the reference sample. The $\mathrm{CH}$ content and porosity of samples with $15 \%-25 \%$ silica fume were only $3 \%$ and $5 \%-8 \%$ after 28 d, respectively. However, when $25 \%$ silica fume was replaced, strengths began to decrease due to reduced flowability and slightly increased porosity.

(2) The interfacial bond properties can be successfully evaluated by the simple double-side pullout testing method. The properties of matrix influenced the quality of ITZ and pullout behavior. UHSC containing $15 \%$ to $25 \%$ silica fume showed significantly improvement in pullout behavior with bond strength and pullout energy over $3 \mathrm{MPa}$ and $120 \mathrm{~N}-\mathrm{mm}$ at $28 \mathrm{~d}$, respectively. Formation of more and higher strength of hydration products and refinement of ITZ around the fiber ensured higher micro-hardness, and thus increased the bond to fiber.

\section{Acknowledgements}

The research was financially supported by the National Science Foundation of China under project Nos. U1305243 and 51378196, Energy Consortium Research Center of Missouri S\&T under grant No. SMR-1406-09, and the RE-CAST University Transportation Center at Missouri S\&T under grant No. DTRT13-G-UTC45. The authors would like to acknowledge the assistance of Jian Zhang, Linmei Wu, and Weina Meng for carrying some of the experimental investigation.

\section{References}

[1] Richard P, Cheyrezy M. Reactive powder concretes with high ductility and 200-800 MPa compressive strength. ACI Mater J 1994; 144(3): 507-518.

[2] Shi CJ, Wu ZM, Xiao JF, Wang DH, Huang ZY, Fang Z. A Review on Ultra High Performance 
Concrete Part I: Raw Materials and Mixture Design. Constr Build Mater 2015; 101: 741-751.

[3] Wang DH, Shi CJ, Wu ZM, Xiao JF, Huang ZY, Fang Z. A Review on Ultra High Performance Concrete Part II: Hydration, Microstructure and Performance. Constr Build Mater 2015; 96: 368-377.

[4] Wille K, Naaman AE. Effect of ultra-high-performance concrete on pullout behavior of high-strength brass-coated straight steel fibers. ACI Mater J 2013; 110(4); 451-461.

[5] Yoo DY, Shin HO, Yang JM, Yoon YS. Material and bond properties of ultra high performance fiber reinforced concrete with micro steel fibers. Composites: Part B 2014; 58, 122-133.

[6] Lee SF, Jacobsen S. Study of interfacial microstructure, fracture energy, compressive energy and debonding load of steel fiber-reinforced mortar. Mater Struct 2011; 44(8): 1451-1465.

[7] $\mathrm{Li} \mathrm{VC,} \mathrm{Wu} \mathrm{HC,} \mathrm{Chan} \mathrm{YW.} \mathrm{Effect} \mathrm{of} \mathrm{plasma} \mathrm{treatment} \mathrm{of} \mathrm{polyethylene} \mathrm{fibers} \mathrm{on} \mathrm{interface} \mathrm{and}$ cementitious composite properties. Journal of the American Ceramic Society 1996; 79(3), 700-704.

[ 8] Wille K, Naaman AE. Pullout behavior of high-strength steel fiber embedded in ultra-high-performance concrete. ACI Mater J 2012; 109(4): 479-487.

[9] Chan YW, Chu SH. Effect of silica fume on steel fiber bond characteristics in reactive powder concrete. Cem Concr Res 2004; 34: 1167-1172.

[10] Wu ZM, Shi CJ, He W, LM Wu. Effects of steel fiber content and shape on mechanical properties of ultra high performance concrete. Constr Build Mater, 2016, 103: 8-14.

[11] Scrivener KL. Nemati KM. The percolation of pore space in the cement paste/aggregate interfacial zone of concrete. Cem Concr Res 1996; 26(1): 35-40.

[12] Wang XH, Jacobsen S, He JY, Zhang ZL et al. Application of nanoindentation testing to study of 
the interfacial transition zone in steel fiber reinforced mortar. Cem Concr Res 2009; 39(8), 701-715.

[13] Rangaraju, PR, Jan O, and Sidney D. An investigation into the influence of inter-aggregate spacing and the extent of the ITZ on properties of Portland cement concretes. Cem Concr Res 2010; 40(11), 1601-1608.

[14] Wang XH, Jacobsen S, Lee SF, He JY, Zhang ZL. Effect of silica fume, steel fiber and ITZ on the strength and fracture behavior of mortar. Mater Struct 2010; 43(1-2): 125-139.

[15] Wu ZM, Shi CJ. Gao PW et al. Effects of deicing salts on the salt scaling resistance of concrete. J. Mater. Civ. Eng. 2014, 27 (5): 04014160-1-04014160-11.

[16] Kim DJ, El-Tawil S, Naaman AE. Effect of matrix strength on pull-out behavior of high strength deformed steel fibers, ACI Special Publication. SP272-7, 2010; 135-150.

[17] Park SH, Ryu GS, Koh KT, Kim DJ. Effects of shrinkage reducing agent on pullout resistance of high-strength steel fibers embedded in ultra-high-performance concrete. Cem Concr Compos 2014; 49: 59-69.

[18] Kang SH, Kim JJ, Kim DJ, Chung Y-S. Effects of sand grain size and sand to cement ratio on the interfacial bond strength of steel fibers embedded in mortars. Constr Build Mater 2013; 45: 1104-1116.

[19] Taher AL, Sameer H, William H, Brian Z. Effect of matrix strength on pullout behavior of steel fiber reinforced very-high strength concrete composites. Constr Build Mater 2011; 25: 39-46.

[20] Gray RJ. Experimental techniques for measuring fibre/matrix interfacial bond shear strength. In: Testing, evaluation and quality control of composites. UK: Butterworth Scientific Ltd.; 1983. p. 3-11. [21] Lee Y, Kang ST, Kim JK. Pullout behavior of inclined steel fiber in an ultra-high strength 
cementitious matrix. Constr Build Mater 2010; 24 2030-2041.

[22] Chan YW, Chu SH. Effect of silica fume on steel fiber bond characteristics in reactive powder concrete. Cem Concr Res 2004; 34: 1167-1172.

[23] Chinese national standard. Chinese Cement: Common portland cement, GB175-2007. Beijing, China, 2007.

[24] Shi CJ, Wang DH, Wu LM, Wu ZM. The Hydration and Microstructure of Ultra High-Strength Concrete with Cement-Silica Fume-Slag Binder. Cem Concr Compos 2015; 61: 44-52.

[25] Chinese national standard. Test methods for flowability of cement paste, GB2419-2005, Beijing, China, 2005.

[26] China National Standards. Method of testing cements - determination of strength, GB/T 17671-1999, Beijing, China (in Chinese), 1999.

[27] Chinese national standard. The test method for property of bond between steel fiber and motar. CECS13-2009. 64-68, Beijing, China, 2009.

[29] Washburn EW. Note on a method of determining the distribution of pore sizes in a porous material. Proc Nati Acad Sci USA 1921; 7: 115-116.

[30] Kadri EH, Duval R. Hydration heat kinetics of concrete with silica fume. Constr Build Mater 2009; 23(11): 3388-3392.

[31] Vikan H, Justnes H. Rheology of cementitious paste with silica fume or limestone. Cem Concr Res 2007; 37(11): 1512-1517.

[32] Lura P, Jensen OM, and Breugel, KV. Autogenous shrinkage in high-performance cement paste: an evaluation of basic mechanisms. Cem Concr Res 2003; 33(2): 223-232. 
[33] Zhang W, Zhang Y, Liu L, Zhang G, Li Z. Investigation of the influence of curing temperature and silica fume content on setting and hardening process of the blended cement paste by an improved ultrasonic apparatus. Constr Build Mater 2012; 33, 32-40.

[34] Esteves LP. On the hydration of water-entrained cement-silica systems: combined SEM, XRD and thermal analysis in cement pastes, Thermochim. Acta, 2012; 518 (1-2) 27-35.

[35] Ye G, Liu X, De Schutter G, Poppe AM, Taerwe L. Influence of limestone powder used as filler in SCC on hydration and microstructure of cement pastes, Cem Concr Compos 2007; 29 (2) 94-102.

[36] Pane I, Hansen W. Investigation of blended cement hydration by isothermal calorimetry and thermal analysis, Cem Concr Res 2005; 35 (6): 1155-1164.

[37] Zhang TS, Yu QJ, Wei JX, Gao P et al. Micro-structural development of gap-graded blended cement pastes containing a high amount of supplementary cementitious materials. Cem Concr Compos 2012; 34(9): 1024-1032.

[38] Halamickova P, Detwiler RJ, Bentz DP, Garboczi EJ. Water permeability and chloride ion diffusion in Portland cement mortars: relationship to sand content and critical pore diameter, Cem Concr Res 1995; 25 790-802.

[39] Ghafari E, Costa H, Júlio E et al. The effect of nanosilica addition on flowability, strength and transport properties of ultra high performance concrete. Materials and Design 2014; 59: 1-9.

[40] Metha PK, Monterio PJM. Concrete, Microstructure, Properties and Materials. McGraw-Hill, London, 2006.

[41] Zeng Q, Li KF, Chong TF, Dangla P. Pore structure characterization of cement pastes blended with high-volume fly-ash. Cem Concr Res 2012; 42(1): 194-204. 
[42] Jennings HM. A model for the microstructure of calcium silicate hydrates in cement paste. Cem Concr Res 2000; 30: 101-116.

[43] Naaman AE, Namur GG, Alwan JM, Najm HS. Fiber pullout and bond slip I: analytical study. J Struct Eng 1991; 117(9): 2769-2790.

[44] Naaman AE, Namur GG, Alwan JM, Najm HS. Fiber pullout and bond slip II: experimental validation. J Struct Eng 1991; 117(9): 2791-2800.

[45] Chan, YW, and Li VC. Age effect on the characteristics of fibre/cement interfacial properties. Journal of Materials Science 1997; 32(19): 5287-5292.

[46] Masse S, Zanni H, Lecourtier J, Roussel JC, Rivereau A. ${ }^{29}$ Si solid state NMR study of tricalcium silicate and cement hydration at high temperature. Cem Concr Res 1993; 23(5): 1169-1177.

[47] Yang SL, Millardb SG, Soutsosb MN, Barnettb SJ, Leb TT. Influence of aggregate and curing regime on the mechanical properties of ultra-high performance fibre reinforced concrete (UHPFRC). Constr Build Mater 2009; 23(6): 2291-2298.

[48] Sorelli L, Constantinides G, Ulm FJ, et al. The nano-mechanical signature of ultra high performance concrete by statistical nanoindentation techniques. Cem Concr Res 2008; 38(12): $1447-1456$.

[49] Setter N., Roy DM. Mechanical features of chemical shrinkage of cement paste. Cem Concr Res 1978; 8(5): 623-634.

[50] Jensen OM, Hansen PF, Autogenous deformation and change of the relative humidity in silica fume-modified cement paste, ACI Mater. J. 1996; 93(6): 539-543. 
Table Captions

Table 1 Chemical composition and physical properties of binder Table 2 Mixture proportion of UHSC

Table 3 Micro-hardness of matrix around fiber 
Figure Captions

Fig. 1 Illustration of dog-bone shape specimen

Fig. 2 Illustration of pullout test apparatus

Fig. 3 Mini slump flow of UHSCs with different silica fume contents

Fig. 4 Heat evolution rate of UHSCs with different silica fume contents

Fig. 5 Effect of silica fume content on compressive and flexural strengths of UHSCs mixture

Fig. 6 TG and DTG curves of UHSCs mixture with different silica fume contents at $28 \mathrm{~d}$

Fig. 7 TG and DTG curves of U15 and U20 samples at different curing ages

Fig. 8 Content of $\mathrm{CH}$ in UHSCs from TG analyses

Fig. 9 Pore structure of UHSCs with different silica fume contents at 1 and $28 \mathrm{~d}$

Fig. 10 Pore structure of U20 mixture at different ages

Fig. 11 Pore volume distribution of UHSCs

Fig. 12 Effect of silica fume content on pullout load-slip curves of UHSCs

Fig. 13 Effect of silica fume on fiber bonding strength of UHSCs at different ages

Fig. 14 Effect of silica fume content on pullout energy of UHSCs

Fig. 15 BSEM images of U20 samples with an embedded fiber 